\title{
Hyperspectral analysis of snow reflectance to understand the effects of contamination and grain size
}

\author{
S.K. SINGH, ${ }^{1}$ A.V. KULKARNI, ${ }^{1}$ B.S. CHAUDHARY ${ }^{2}$ \\ ${ }^{1}$ Marine and Earth Sciences Group (MESG), Space Applications Centre (ISRO), Ahmedabad 380 015, India \\ E-mail: sushil@sac.isro.gov.in \\ ${ }^{2}$ Department of Geophysics, Kurukshetra University, Kurukshetra 136 119, India
}

\begin{abstract}
Reflectance data for contaminated and different grain-size snow were collected using a spectroradiometer ranging from 350 to $2500 \mathrm{~nm}$. Contamination was predominantly due to soil. The radiometer data were binned at $10 \mathrm{~nm}$ intervals by averaging, and then principal component analysis, shape, size and strength of the absorption peak, first and second derivatives were computed, providing information about the effect of grain size and contamination on snow reflectance. Relative strength for contamination and grain size showed a distinct reverse pattern at $\mathbf{1 0 2 5} \mathbf{~ n m}$ after continuum removal. Band absorption depth at $1025 \mathrm{~nm}$ showed an increase with increasing snow grain size, whereas the band depth was found to decrease with increased soil contamination. The curve shape was right asymmetric and showed a change to left asymmetry with increase in contamination. The first derivative of reflectance in the visible region showed a shift of peak due to contamination. Soil contamination significantly reduced the albedo of snow at a low level of contamination but showed little influence at higher level. Relative strength, shape of curve and reflectance characteristics have shown the potential to identify the influence of contamination and grain-size based metamorphism using satellite-based hyperspectral remote sensing.
\end{abstract}

\section{INTRODUCTION}

Snow plays an important role in hydrological and climatic applications in mountainous regions. Field measurements of snow properties provide point observation but are restricted to limited locations due to rough terrain and harsh weather conditions. Remote sensing provides information about snow properties, which conventionally is not available for large areas due to typical terrain conditions. Snow shows high reflectance in the visible wavelength region and low reflectance in the shortwave infrared (SWIR) region. This spectral property of snow was used for snow-cover monitoring on a regular basis using the Moderate Resolution Imaging Spectroradiometer (MODIS) sensor and the Advanced Wide Field Sensor (AWiFS) (Hall and others, 1995, 2002; Kulkarni and others, 2006).

The reflectance of fresh snow is approximately $90 \%$ in the visible region and decreases at longer wavelengths. Freshly fallen snow almost immediately begins to compact and metamorphose, changing the snowpack characteristics. The albedo of fresh snow in the visible region of the spectrum remains high and decreases slowly with age of snow, but in the near-infrared region the albedo of aging snow decreases considerably as compared to fresh snow (O'Brien and Munis, 1975; Warren and Wiscombe, 1980; Wiscombe and Warren, 1980). Wiscombe and Warren (1980) showed that minute concentrations of small highly absorbing particles can lower snow albedo in the visible wavelengths by $5-15 \%$.

Broadband albedo decreases when grain size increases as the snow ages. Melting of snow causes grains to grow clusters and behave as a large single grain (Dozier and others, 1981; Warren, 1982). Gerland and others (1999) measured a maximum albedo more than $90 \%$ on Svalbard, Norway, before melt onset, and $60 \%$ after melt progressed in the spring when the snow was considered old but still clean. Many studies have related the snow reflectance in the nearinfrared (NIR) region to grain-size variability using the
$1.03 \mu \mathrm{m}$ absorption feature by its continuum (Dozier and others, 1981; Nolin and Dozier, 1993, 2000). Snow-cover area, albedo, grain size, snow temperature, wetness and meteorological parameters are required for any snowmelt runoff model. Painter and others (2003) described the multiple end-member snow-covered area and grain-size (MEMSCAG) model which couples spectral mixture analysis with a radiative transfer to map sub-pixel snow-covered area and the grain size of the snow cover simultaneously, without using topographic data.

In undulating terrain like the Himalaya, and especially in the lower Himalayan region, atmospheric conditions change very fast. Temperature varies significantly between day and night, generating melt-freeze cycles. Very few previous studies have used a field spectroradiometer to understand snow characteristics in the Himalayan region. Spectroradiometer data of Beas basin are used in the present study. Contaminated snow shows a decrease in reflectance in the visible region, whereas grain size within the snowpack has more influence in the NIR region (Singh and others, 2005, 2008). Contamination and the effect of mixed objects like vegetation and soil on snow reflectance for the Himalayan region was reported by Negi and others (2009) where different indices were attempted to provide an understanding of snow pixel identification under different scenarios for broadband sensors. But the increasing number of airborne/satellite hyperspectral sensors like the Airborne Visible/Infrared Imaging Spectrometer (AVIRIS) provides an opportunity to measure the absorption spectrum and its utilities to improve applications (Gao and others, 1993; Price, 1998). Green and others (2006) estimated the abundance of the three phases of water, i.e. water vapour, liquid water and ice, using AVIRIS over Mount Rainier, Washington, USA. Contamination and grain-size variability strongly influence the reflected albedo from snowpack and need to be characterized based on narrowband channel 

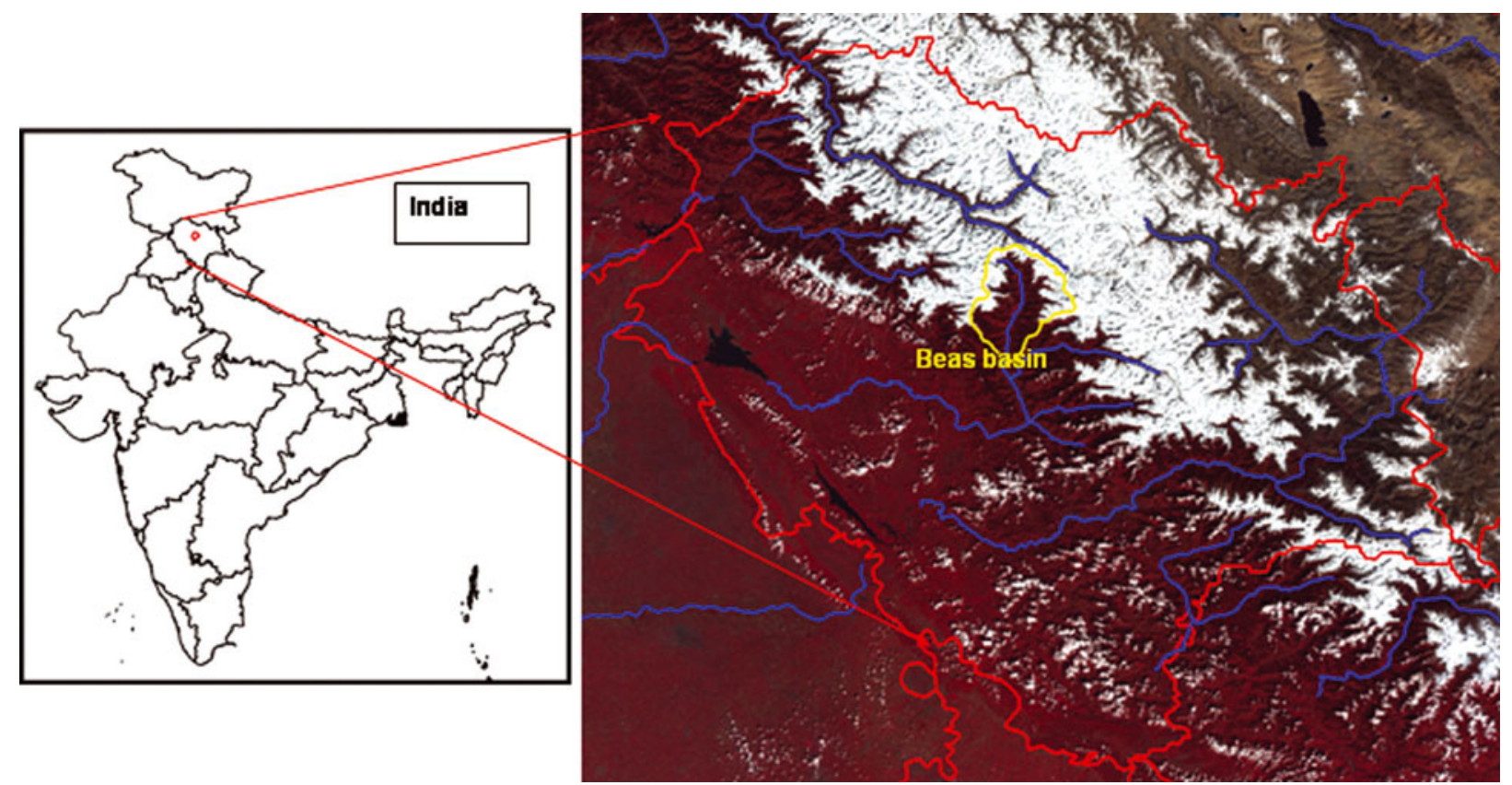

Fig. 1. IRS AWiFS image superimposed with Beas basin boundaries.

information. Selection and identification of proper bands is essential to reduce the redundancy in acquired information. Snowpack albedo, which is an essential input to a snowmelt model, is affected by contamination in the visible region and by grain size in the NIR region. In the present study, the possibility of identifying the contamination- and grain-sizebased metamorphism was explored using field-based hyperspectral data available from the satellite platform. This study attempts to provide a set of information which can be used to identify the contamination and grain size of a snowpack simultaneously.

\section{STUDY AREA}

Beas basin was selected as the study area for this experiment; it is in the Pir Panjal range, at 2000-4000 m a.s.l. It is characterized by moderate temperature and high precipitation. Snowfall takes place even in the lower ridges

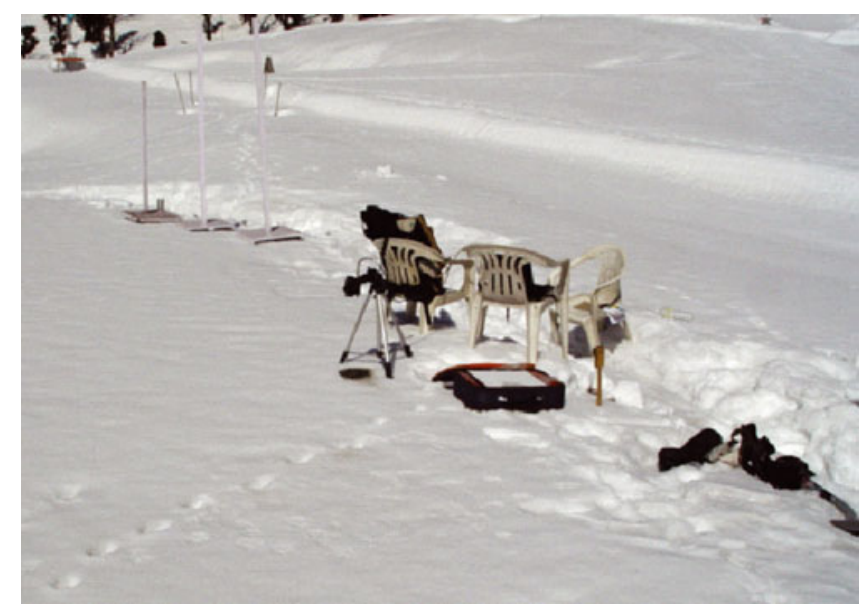

Fig. 2. Field set-up of ASD spectroradiometer for soil contamination experiment. of the basin, and the approach of summer sees snowmelt take place. Due to moderate temperature, the snow cover changes into isothermal snowpack at $0^{\circ} \mathrm{C}$ and the winter period remains short. A location map of Beas basin is shown in Figure 1. Snow and Avalanche Study Establishment (SASE) observatories, which were used for snow reflectance and other collateral data collection in the present study, are established at Bahang $\left(32.27^{\circ} \mathrm{N}, 77.15^{\circ} \mathrm{E} ; 2192 \mathrm{~m}\right.$ a.s.I.), Solang $\left(32.32^{\circ} \mathrm{N}, 77.16^{\circ} \mathrm{E} ; 4480 \mathrm{ma.s.l}\right.$.) and Dhundi $\left(32.36^{\circ} \mathrm{N}, 77.13^{\circ} \mathrm{E} ; 3050 \mathrm{~m}\right.$ a.s.l.) (Mohile and others, 2004). These observatories receive a significant amount of seasonal snowfall on average between November and April (Bahang $53 \mathrm{~cm}$, Solang $127 \mathrm{~cm}$ and Dhundi $219 \mathrm{~cm}$ ), and temperature remains high in this area compared to the other Himalayan ranges (at Bahang, $T_{\max }=21^{\circ} \mathrm{C}$ and $T_{\min }=$ $-0.44^{\circ} \mathrm{C}$, at Solang, $T_{\max }=15^{\circ} \mathrm{C}$ and $T_{\min }=-3.9^{\circ} \mathrm{C}$ and at Dhundi $T_{\max }=11^{\circ} \mathrm{C}$ and $T_{\min }=-4.7^{\circ} \mathrm{C}$, from November to April, 1971-97) (Mohile and others, 2004).

\section{FIELD SET-UP AND DATA COLLECTION}

We used an ASD spectroradiometer, which collects radiometric quantities like radiance, reflectance and irradiance in the spectral range $350-2500 \mathrm{~nm}$. It collects the data at a spectral resolution of $3 \mathrm{~nm}$ in the visible and NIR region, and $10-12 \mathrm{~nm}$ in the SWIR region. The bare-fibre $25^{\circ}$ field of view was used. Figure 2 depicts the experimental set-up of the ASD instrument during field investigations. A crystal gauge with a magnifying glass was used to estimate the snow grain size. A thermometer was used for snow surface temperature and air-temperature measurements.

\section{METHODOLOGY}

A varying amount of contamination and grain size was considered. To observe the effects of contamination, contaminant-like soil was used in varying quantities. During the experiment the soil was dried, grinded and filtered. It was 


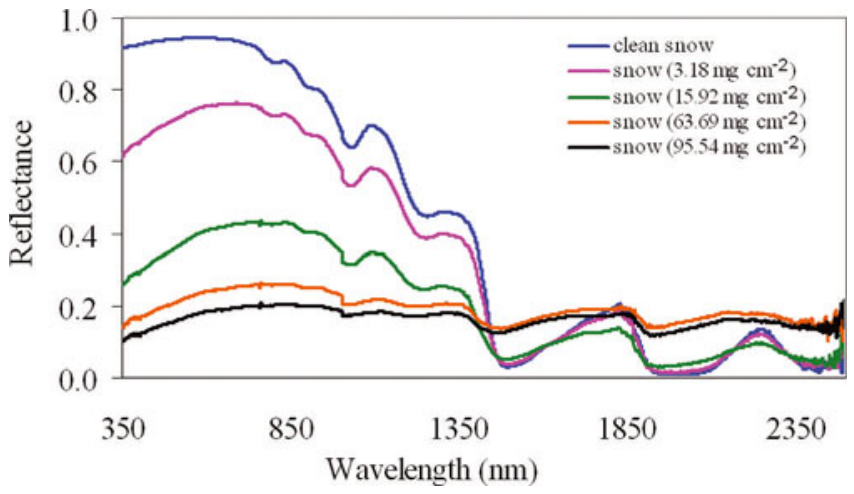

Fig. 3. Snow reflectance for varying amount of soil contamination.

weighed into 1, 5, 20 and $30 \mathrm{~g}$ packets which were equally distributed over the study area. The snow was moist, with a density of $240 \mathrm{~kg} \mathrm{~m}^{-3}$ and a grain size of $0.1-0.6 \mathrm{~mm}$. The instrument sensor was kept at a height so that the view area on the surface had a diameter of $20 \mathrm{~cm}$. Measurements were taken for clean snow and after spraying 1, 5, 20 and $30 \mathrm{~g}$ soil equally on the surface. Reflectance data were collected using a bare-fibre sensor $\left(25^{\circ}\right.$ field of view), and the average of 15 measurements was determined. Soil contamination was $0.0,3.18,15.92,63.69$ and $95.54 \mathrm{mg} \mathrm{cm}^{-2}$ on the snowcovered surface (Fig. 3). The duration of measurements was 10-15 min to avoid any other ambient influences due to change in sun-sensor viewing geometry and physical/ meteorological conditions. Albedo was computed for each category of added soil contamination during the experiment. Snow grain-size data were collected in natural conditions and divided into fine $(<0.5 \mathrm{~mm})$, medium $(<1.0 \mathrm{~mm})$ and coarse (1.0-2.0 mm) categories using a crystal gauge (Fig. 4). There is minimal human intervention in the study area, so it is assumed that no other disturbing effects exist.

Field-based hyperspectral data were binned at $10 \mathrm{~nm}$ intervals using simple averaging which is compatible with the available hyperspectral satellite sensor's spectral resolution and also with the spectral resolution of the field spectroradiometer at SWIR wavelengths with the assumption of square-wave response function. Principal components analysis (PCA) was carried out using the statistical software SPSS V-10 (SPSS Inc., 1999). Only those principal components with eigenvector values $>1$ were considered.

Different wavelength regions were chosen based on the influence of physical change on the snowpack characteristics. Position, strength and shape of a spectral curve can provide the information on smoothly varying spectral properties. The absorption peak at $1025 \mathrm{~nm}$ was chosen, as this is influenced by the grain-size variability. The relative strength, width and asymmetry of the absorption feature were computed after continuum removal for different wavelength regions. The objective of continuum removal is to isolate the properties of the absorption features from the overall reflectance properties. The relative strength of each band is computed using the formula (Clark and Roush, 1984)

$$
S=\frac{R_{\mathrm{C}}-R_{\mathrm{b}}}{R_{\mathrm{C}}}
$$

where $S$ is the band strength, $R_{\mathrm{C}}$ is the reflectance of the continuum at the wavelength of $R_{\mathrm{b}}$, and $R_{\mathrm{b}}$ the reflectance at the band minimum.

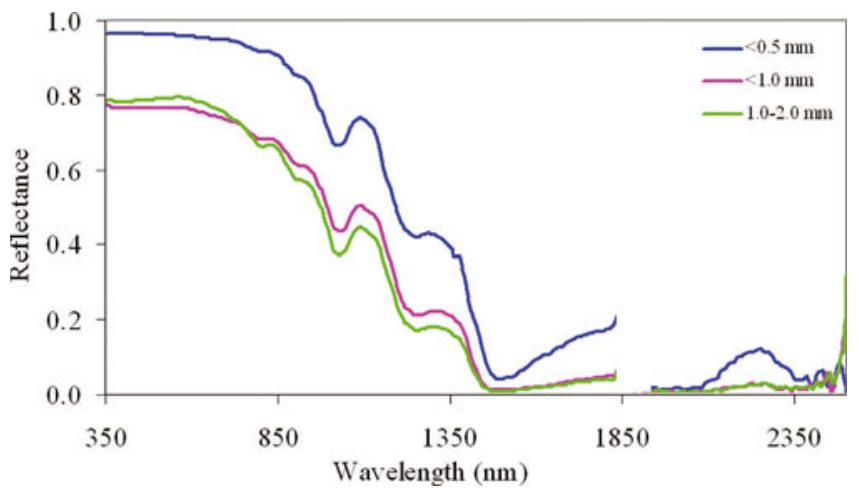

Fig. 4. Snow reflectance for varying grain size.

Band shape can be parameterized for the purposes of this systematic analysis by two simple parameters such as full width at half-maximum and asymmetry. The width of a feature is the absolute difference in microns between the right and left sides of absorption, where the reflectances are half the strength of the band. Asymmetry is defined as the base 10 logarithm of the sum of the reflectance over the number of channels to the right of the band minimum divided by the sum of the reflectance over the numbers of channels to the left of the band minimum. A zero value represents a perfectly symmetric band, a positive value right asymmetry and a negative value left asymmetry.

$$
\text { Asymmetry }=\log _{10}\left(\frac{\sum R_{\mathrm{c} \rightarrow \mathrm{right}}}{\sum R_{\text {left } \rightarrow \mathrm{c}}}\right),
$$

where $R_{\mathrm{c} \rightarrow \text { right }}$ represents the reflectance from centre to right, and $R_{\text {left } \rightarrow \text { c }}$ the reflectance from left to centre, of the wavelength of the absorption peak. This parameterization, like band depth and asymmetry, allows rapid reduction in the dimensionality of a spectroradiometer dataset into discrete key absorption features of the obtained spectrum. The first and second derivatives were computed, which indicated any change in shape of the curve at particular wavelengths. Changes in percentage of reflectance were computed with contaminants (soil) and for varying grain size.

\section{RESULTS AND DISCUSSIONS}

The influence of soil contamination and grain size on snow reflectance was considered, with a view to using this information in hyperspectral remote sensing. Figure 3 shows the reflectance behaviour of snow with a changing amount of contamination, and Figure 4 the grain-size variability of snow reflectance. A significant decrease in reflectance due to soil contamination is seen in the visible and NIR region, with a lesser decrease due to change in grain size. It is also observed that the absorption peak at $1025 \mathrm{~nm}$ almost diminishes for 63.69 and $95.54 \mathrm{mg} \mathrm{cm}^{-2}$ amount of soil contamination, whereas it is still significant for varying grain size. The relative strength at $1025 \mathrm{~nm}$, after continuum removal, shows a decreasing trend in soil contamination, whereas a reverse pattern of increasing relative strength is observed for grain size (Fig. 5).

Tables 1 and 2 show the relative strength and asymmetric nature of the absorption peak in the NIR region. Relative strength decreases except for the $15.92 \mathrm{mg} \mathrm{cm}^{-2}$ soil contamination level at $1025 \mathrm{~nm}$ which can be explained 

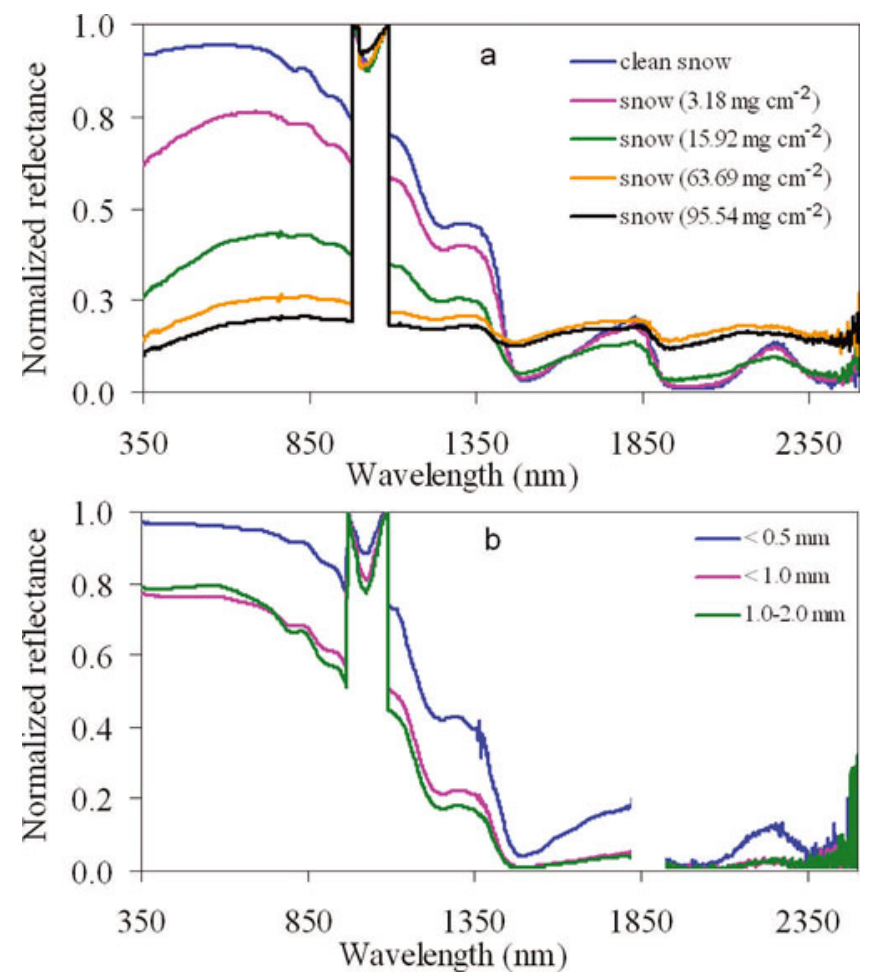

Fig. 5. Continuum removal of field-based radiometric data: (a) soil contamination and (b) grain size.

with the help of Table 2. The absorption peak is right asymmetric at $1025 \mathrm{~nm}$ and was systematically asymmetric towards the left. Hence, the relative strength at $1000 \mathrm{~nm}$ shows a clearer picture of decreasing relative strength due to increase in soil contamination level. Asymmetry at $1085 \mathrm{~nm}$ is not very significant.

The relative strength at $1025 \mathrm{~nm}$ due to grain size shows an increasing pattern (Table 3). The absorption peak at $1025 \mathrm{~nm}$ shows a right asymmetric nature (Table 4). The shape is inclined towards the left side but only from fine grain to medium grain, and no difference was observed in the shape of the peak from medium to coarse grain. However, asymmetry at $1085 \mathrm{~nm}$ is systematically asymmetric towards the right. The peak shift is also seen very clearly in the first derivative of soil contamination and grain size (Fig. 6). Figure 6 shows a peak shift in the visible region due to the addition of contamination which is not present for varying grain size. As the contamination level increases from clean snow to highly contaminated snow, the shift moves from $575 \mathrm{~nm}$ to $735 \mathrm{~nm}$. The width of the absorption feature

Table 1. Relative strengths of absorption feature at $1025 \mathrm{~nm}$ and $1000 \mathrm{~nm}$ for contaminated snow

\begin{tabular}{lcc}
\hline Contamination & \multicolumn{2}{c}{ Relative strength of peak } \\
& At $1025 \mathrm{~nm}$ & At $1000 \mathrm{~nm}$ \\
\hline Clean snow & 0.116 & 0.069 \\
Soil & & \\
$3.18 \mathrm{mg} \mathrm{cm}^{-2}$ & 0.119 & 0.061 \\
$15.92 \mathrm{mg} \mathrm{cm}^{-2}$ & 0.128 & 0.05 \\
$63.69 \mathrm{mg} \mathrm{cm}^{-2}$ & 0.101 & 0.015 \\
$95.54 \mathrm{mg} \mathrm{cm}^{-2}$ & 0.066 & 0.015
\end{tabular}

Table 2. Asymmetry of absorption feature at $1025 \mathrm{~nm}$ and $1085 \mathrm{~nm}$ for contaminated snow

Contamination Asymmetry of peak

At $1025 \mathrm{~nm} \quad$ At $1085 \mathrm{~nm}$

\begin{tabular}{lll}
\hline $\begin{array}{l}\text { Clean snow } \\
\text { Soil }\end{array}$ & 0.143 & 0.010 \\
$3.18 \mathrm{mg} \mathrm{cm}^{-2}$ & 0.141 & \\
$15.92 \mathrm{mg} \mathrm{cm}^{-2}$ & 0.140 & 0.011 \\
$63.69 \mathrm{mg} \mathrm{cm}^{-2}$ & 0.132 & 0.014 \\
$95.54 \mathrm{mg} \mathrm{cm}^{-2}$ & 0.141 & 0.013 \\
& & 0.011 \\
\hline
\end{tabular}

Table 3. Relative strengths of absorption feature at $1025 \mathrm{~nm}$ for different snow grain sizes

\begin{tabular}{lcc}
\hline Grain size & \multicolumn{2}{c}{ Relative strength of peak } \\
& At $1025 \mathrm{~nm}$ & At $1000 \mathrm{~nm}$ \\
\hline$<0.5 \mathrm{~mm}$ & 0.118 & 0.076 \\
$<1.0 \mathrm{~mm}$ & 0.191 & 0.116 \\
$1-2 \mathrm{~mm}$ & 0.226 & 0.139 \\
\hline
\end{tabular}

was found to be within $6 \mathrm{~nm}$ range at $1025 \mathrm{~nm}$ from clean to highly contaminated snow. Albedo decreased as the contamination level increased. However, the albedo was drastically reduced $(\sim 25 \%)$ for the already small amount of soil contamination, and further reduction in albedo was not significant $(\sim 5 \%)$ for the higher amount of contamination. Albedo was reduced by $\sim 12 \%$ from fine to medium grain size, but there was no significant reduction from medium to coarse grain size (Fig. 7). Tables 5 and 6 show reflectance and percentage change in reflectance for a few optimum important bands for contamination and grain-size variability study. SWIR 1 and SWIR 2 show opposite patterns for contamination and grain-size metamorphism, especially for higher levels of contamination. They show a significant reduction in reflectance from fine to medium and coarse grain size.

Relative strength, asymmetry and peak shift show a squeezing of snow spectrum from the visible to the NIR region for contamination which is not present for varying grain size. This is an important observation which shows the possibility of identifying snow metamorphism due to contamination and grain-size variability on a temporal basis using hyperspectral remote sensing.

Table 4. Asymmetry of absorption feature at $1025 \mathrm{~nm}$ and $1085 \mathrm{~nm}$ for different snow grain sizes

Grain size Asymmetry of peak

$$
\text { At } 1025 \mathrm{~nm} \quad \text { At } 1085 \mathrm{~nm}
$$

\begin{tabular}{lll}
\hline$<0.5 \mathrm{~mm}$ & 0.153 & 0.006 \\
$<1.0 \mathrm{~mm}$ & 0.142 & 0.017 \\
$1.0-2.0 \mathrm{~mm}$ & 0.141 & 0.020
\end{tabular}



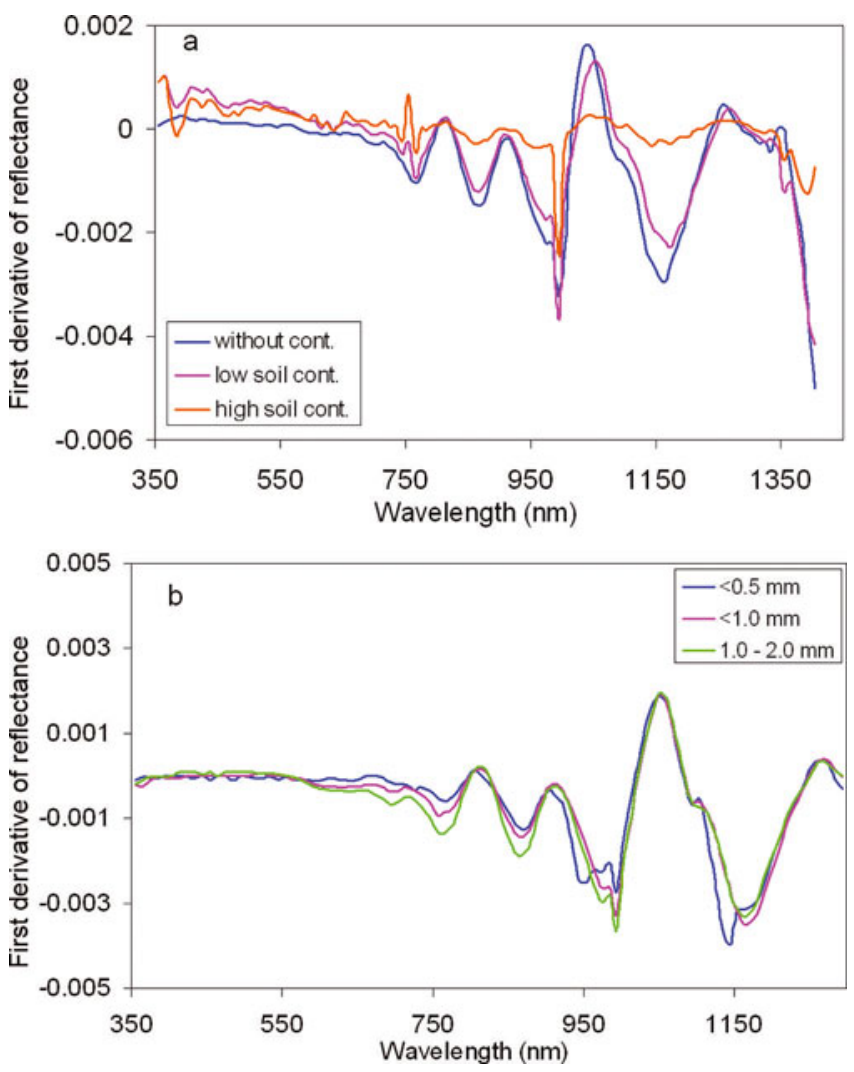

Fig. 6. First derivative of reflectance of (a) contamination and (b) grain size.

\section{CONCLUSIONS}

Radiometric data for different soil contamination and varying grain size were collected in controlled conditions in the Himalayan region. Relative strength, asymmetry, width, first derivative, albedo and percentage change in reflectance were used to analyse the field data. Relative strength, asymmetry and first derivative of reflectance show that as the soil contamination increased, a squeezing of snow spectrum was observed in the visible to NIR region of spectrum. Peak width was not significant for soil contamination and grain size (within 5-6 nm) at $1025 \mathrm{~nm}$. Different levels of contamination resulted in a decrease in relative strength at $1025 \mathrm{~nm}$ and $1000 \mathrm{~nm}$. Increasing grain size caused an increase in relative strength at $1025 \mathrm{~nm}$ in the
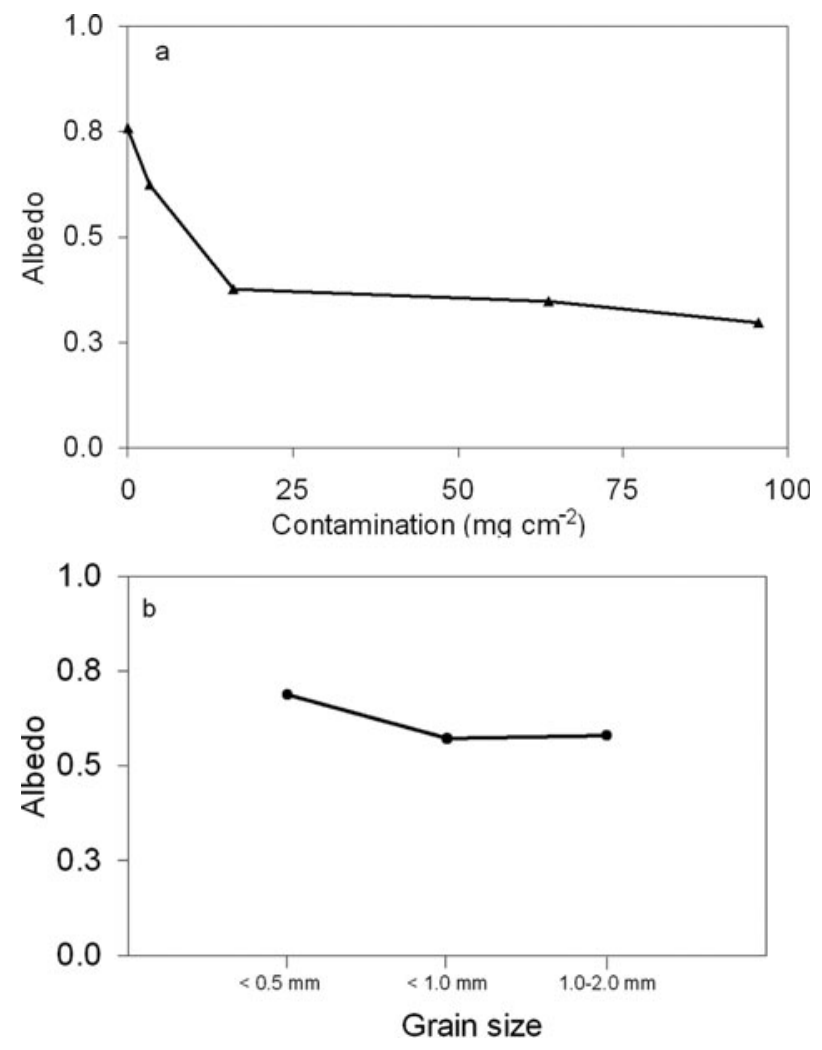

Fig. 7. Effect of (a) soil contamination and (b) grain size on albedo.

Himalayan region, as has also been reported by Nolin and Dozier (2000) using AVIRIS data. A combination of these two observations is helpful to differentiate contamination- or grain-size-based snow metamorphism using temporal information. Both soil contamination and grain size have a right asymmetric absorption peak at $1025 \mathrm{~nm}$, but soil contamination shows a systematic tendency towards left asymmetry of curve shape with increase in soil contamination level. Albedo significantly decreased due to the already low level of contamination $(\sim 25 \%)$ and did not decrease much further for higher soil contamination levels. This observation suggests that contamination can initially drastically reduce the albedo but almost saturates if the snow is further contaminated.

Table 5. Percentage change in reflectance, $R$, for selected bands from visible to SWIR region due to varying contamination amount

\begin{tabular}{|c|c|c|c|c|c|c|c|c|c|}
\hline \multirow{4}{*}{$\begin{array}{c}\lambda \\
\mathrm{nm}\end{array}$} & \multicolumn{5}{|c|}{ Reflectance } & \multicolumn{4}{|c|}{$\%$ change in reflectance } \\
\hline & \multirow[t]{2}{*}{ Clean snow } & \multicolumn{4}{|c|}{ Soil } & \multicolumn{4}{|c|}{ Soil } \\
\hline & & $\begin{array}{c}3.14 \\
\mathrm{mg} \mathrm{cm}^{-2}\end{array}$ & $\begin{array}{c}15.92 \\
\mathrm{mg} \mathrm{cm}^{-2}\end{array}$ & $\begin{array}{c}63.69 \\
\mathrm{mg} \mathrm{cm}^{-2}\end{array}$ & $\begin{array}{c}95.54 \\
\mathrm{mg} \mathrm{cm}^{-2}\end{array}$ & $\begin{array}{c}3.14 \\
\mathrm{mg} \mathrm{cm}^{-2}\end{array}$ & $\begin{array}{c}15.92 \\
\mathrm{mg} \mathrm{cm}^{-2}\end{array}$ & $\begin{array}{c}63.69 \\
\mathrm{mg} \mathrm{cm}^{-2}\end{array}$ & $\begin{array}{c}95.54 \\
\mathrm{mg} \mathrm{cm}^{-2}\end{array}$ \\
\hline & & & & & & & & & \\
\hline 585 & 0.9460 & 0.7507 & 0.4025 & 0.2365 & 0.1809 & 20.64 & 57.45 & 75.00 & 80.88 \\
\hline 695 & 0.9349 & 0.7607 & 0.4270 & 0.2533 & 0.1960 & 18.63 & 54.33 & 72.91 & 79.04 \\
\hline 745 & 0.9185 & 0.7539 & 0.4305 & 0.2570 & 0.2000 & 17.92 & 53.14 & 72.02 & 78.23 \\
\hline 1025 & 0.6404 & 0.5329 & 0.3144 & 0.2038 & 0.1735 & 16.78 & 50.91 & 68.17 & 72.90 \\
\hline 1085 & 0.6996 & 0.5816 & 0.3451 & 0.2155 & 0.1815 & 16.87 & 50.68 & 69.20 & 74.06 \\
\hline 1645 & 0.1067 & 0.1066 & 0.1011 & 0.1788 & 0.1656 & 0.09 & 5.28 & -67.55 & -55.20 \\
\hline 2265 & 0.1274 & 0.1155 & 0.0913 & 0.1754 & 0.1570 & 9.28 & 28.34 & -37.69 & -23.27 \\
\hline
\end{tabular}


Table 6. Percentage change in reflectance for different grain sizes

\begin{tabular}{|c|c|c|c|c|c|c|c|c|}
\hline \multirow[t]{2}{*}{ Grain size } & \multicolumn{4}{|c|}{ Reflectance } & \multicolumn{4}{|c|}{$\%$ change in reflectance } \\
\hline & $1025 \mathrm{~nm}$ & $1085 \mathrm{~nm}$ & $1645 \mathrm{~nm}$ & $2265 \mathrm{~nm}$ & $1025 \mathrm{~nm}$ & $1085 \mathrm{~nm}$ & $1645 \mathrm{~nm}$ & $2265 \mathrm{~nm}$ \\
\hline$<0.5 \mathrm{~mm}$ & 0.6642 & 0.7392 & 0.1139 & 0.1146 & - & - & - & - \\
\hline$<1.0 \mathrm{~mm}$ & 0.4334 & 0.5028 & 0.0249 & 0.0278 & 34.7 & 32.0 & 78.13 & 75.73 \\
\hline $1.0-2.0 \mathrm{~mm}$ & 0.3743 & 0.4465 & 0.0215 & 0.0288 & 43.6 & 39.6 & 81.09 & 74.86 \\
\hline
\end{tabular}

This study shows that the $1025 \mathrm{~nm}$ absorption peak is useful not only for detecting grain-size variations but also for studying soil contamination. In the future, relative strength, asymmetry, peak shift, albedo and percentage change in reflectance may be used as a classification scheme to study/ identify the cause of snow metamorphism, i.e. contamination/grain size, using hyperspectral remote sensing.

\section{ACKNOWLEDGEMENTS}

We thank R.R. Navalgund (Director, Space Applications Centre) and J.S. Parihar (Deputy Director, Remote Sensing Applications Area) for their kind support during this study. We also thank Dr Ajai (Group Director, MESG) and T.J. Majumdar (Head, Earth Sciences and Hydrology Division (ESHD)/MESG) for their encouragement. We gratefully acknowledge the help of Snow and Avalanche Study Establishment (SASE) Team Members during the field investigations, and of anonymous reviewers for their critical evaluation of and suggestions on the manuscript.

\section{REFERENCES}

Clark, R.N. and T.L. Roush. 1984. Reflectance spectroscopy: quantitative analysis techniques for remote sensing applications. J. Geophys. Res., 89(B7), 6329-6340.

Dozier, J., S.R. Schneider and D.F. McGinnis, Jr. 1981. Effect of grain size and snowpack water equivalence on visible and nearinfrared satellite observations of snow. Water Resour. Res., 17(4), 1213-1221.

Gao, B.-C., K.B. Heidebrecht and A.F.H. Goetz. 1993. Derivation of scaled surface reflectances from AVIRIS data. Remote Sens. Environ., 44(2-3), 165-178.

Gerland, S. and 6 others. 1999. Physical and optical properties of snow covering Arctic tundra on Svalbard. Hydrol. Process., 13(14), 2331-2343.

Green, R.O., T.H. Painter, D.A. Roberts and J. Dozier. 2006. Measuring the expressed abundance of the three phases of water with an imaging spectrometer over melting snow. Water Resour. Res., 42(W10), W10402. (10.1029/2005WR004509.)

Hall, D.K., G.A. Riggs and V.V. Salomonson. 1995. Development of methods for mapping global snow cover using Moderate Resolution Imaging Spectroradiometer (MODIS) data. Remote Sens. Environ., 54(2), 127-140.
Hall, D.K., G.A. Riggs, V.V. Salomonson, N. DiGirolamo and K.J. Bayr. 2002. MODIS snow-cover products. Remote Sens. Environ., 83(1-2), 181-194.

Kulkarni, A.V., S.K. Singh, P. Mathur and V.D. Mishra. 2006. Algorithm to monitor snow cover using AWiFS data of RESOURCESAT-1 for the Himalayan region. Int. J. Remote Sens., 27(12), 2449-2457.

Mohile, C.M., J.S. Pethkar and N.R. Deshpande. 2004. Climatic variability over western Himalaya. In Proceedings of the International Symposium on Snow Monitoring and Avalanches, 12-16 April 2004, Manali, India. Manali, Snow and Avalanche Study Establishment, 171-200.

Negi, H.S., A.V. Kulkarni and B.S. Semwal. 2009. Study of contaminated and mixed objects snow reflectance in Indian Himalaya using spectroradiometer. Int. J. Remote Sens., 30(2), 315-325.

Nolin, A.W. and J. Dozier. 1993. Estimating snow grain size using AVIRIS data. Remote Sens. Environ., 44(2-3), 231-238.

Nolin, A.W. and J. Dozier. 2000. A hyperspectral method for remotely sensing the grain size of snow. Remote Sens. Environ., 74(2), 207-216

O'Brien, H.W. and R.H. Munis. 1975. Red and near-infrared spectral reflectance of snow. CRREL Res. Rep. 332.

Painter, T.H., J. Dozier, D.A. Roberts, R.E. Davis and R.O. Green. 2003. Retrieval of subpixel snow-covered area and grain size from imaging spectrometer data. Remote Sens. Environ., 85(1), 64-77.

Price, J.C. 1998. An approach for analysis for reflectance spectra. Remote Sens. Environ., 64(3), 316-330.

Singh, S.K., H.S. Negi, G.R.K. Babu, A.V. Kulkarni and J.K. Sharma. 2005. Spectral reflectance investigations of snow and other objects using ASD spectroradiometer. Ahmedabad, Space Applications Centre. (SAC Scientific Note RSAM/SAC/RESIPA/ MWRG-GLI/SN-23/2005.)

Singh, S.K., H.S. Negi and A.V. Kulkarni. 2008. Study of snowpack characteristics using field spectroradiometer in Beas basin, H.P. In Proceedings of the International Workshop on Snow, Ice, Glacier and Avalanches, 7-9 January 2008, Mumbai, India. New Dehli, Tata McGraw-Hill Publishing Company. (Annexure.)

SPSS Inc. 1999. SPSS for Windows, Release 10.0.5. Chicago, IL, SPSS Inc.

Warren, S.G. and W.J. Wiscombe. 1980. A model for the spectral albedo of snow. II. Snow containing atmospheric aerosols. J. Atmos. Sci., 37(12), 2734-2745.

Wiscombe, W.J. and S.G. Warren. 1980. A model for the spectral albedo of snow. I. Pure snow. J. Atmos. Sci., 37(12), 2712-2733. 